\title{
Learning to Communicate
}

Architecture, like culture generally, suffers from a babel of languages, and that has gotten worse in recent decades as the audiences we speak to become more diverse. Architects must communicate not just with the various members of the building team - engineers, contractors, product manufacturers - but with increasingly diverse clients and communities. Meanwhile academics must address not only students and peers, but colleagues in other disciplines with jargon of their own.

Ironically, this has made communication within our field more difficult. The practitioner community has not always made clear to academics its information needs, which has resulted in many researchers pursuing questions of little value to the profession. At the same time, practitioners, most of whom conduct a form of research in the process of designing buildings, rarely share their knowledge with colleagues or colleges of architecture. Too few architects, in other words, see the academic community as an important audience, and so the learning cycle that characterizes other professions remains fairly rudimentary in our field.

Meanwhile too few academics see the practitioner community as an audience for their work. Whether written for granting agencies or for small numbers of peers in other institutions, many academic papers obscure meaning as much as clarify it, suffering from bad grammar, weak construction, vague references, and entirely too much jargon not widely understood by others in the field. So often, this work also lacks concreteness, which is a paradox given the literal concreteness of architecture itself.

The situation may surprise no one. We architects have never been noted for our writing skill, nor do we pay much attention to developing that skill either in college or in practice. We are, instead, visual communicators. The neglect of the written word, however, has come to haunt us. Our value both among clients and within universities has come to depend upon the depth of our knowledge and the adeptness of our written and verbal communication. Sharing knowledge and ideas with each other - architect and academic-has become critical to our thriving as a discipline, and if we don't do a better job at this, other fields will, to our detriment.

THE EDITORS

leader $\left|\mathrm{arq} \cdot \mathrm{vol}_{3} \cdot \mathrm{nO}_{3} \cdot 1999\right| 197$ 


\section{architectural research quarterly}

\section{Subscribe now and save $20 \%$}

This ground-breaking quarterly publication, to be published by Cambridge University Press from 1999, aims to act as an international forum for practitioners and academics by publishing cutting-edge research covering all aspects of architectural endeavour. Fully illustrated throughout, arq includes sections on design, history, theory, environmental design, construction, information technology, and practice. New features for 1999 include an updated and comprehensive reviews section, and investigation which will report on developments in the field, including new building types, methods and products. A further development will be the arq directory - a listing of specialist research and consultancy with an online, cumulative version which aims to provide a lasting and invaluable resource for all. arq presents information in a way that is designed to be accessible to all and is essential reading for practitioners in industry and consultancy as well as for academic researchers. It provides an outlet for all those who wish to disseminate their work to an international audience.
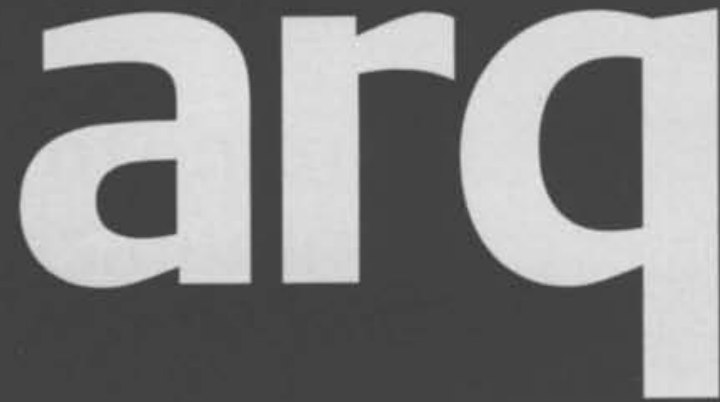

Please enter my subscription to arq: architectural research quarterly, volume 3,1999

E76 (normally E95) institutions print only

E.22 (normally $£_{22}$ ) students

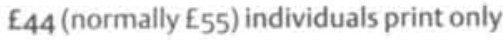

EU residents only. VAT may be payable at your local rate if not registered.

Our VAT registration number: GB 214141614 If registered, your VAT registration no:

Total subscription payment $\mathrm{E}$ Eu residents only, if not registered add VAT at appropriate rate

Total $\mathbf{E}$

Name

Address

\section{Payment enclosed}

Cheque in sterling (payable to Combridge University Press) Bank Draft

Post Office Giro (A/C no 5716055 CB Bootle - please send advice of payment) Credit Card - VISA | MasterCard | American Express (delete where applicable)

Card no

Expiry date

Signature

Photocopy this page and send your order to: Journals Customer Services, Cambridge University Press, Edinburgh Building. Shaftesbury Road,

Cambridge, CB2 2 RU

T +44 (o) 1223326070

F +44 (o) 1223315052

F journals_subscriptions@cup.cam.ac.uk 